\title{
Calcitonin gene-related peptide in blood: is it increased in the external jugular vein during migraine and cluster headache? A review
}

\author{
Peer Tfelt-Hansen · Han Le
}

Received: 15 December 2008/ Accepted: 23 February 2009/Published online: 28 March 2009

(c) The Author(s) 2009. This article is published with open access at Springerlink.com

\begin{abstract}
The involvement of calcitonin gene-related peptide (CGRP) in migraine pathophysiological mechanisms is shown by the facts that CGRP can induce migraine and that two CGRP antagonists, olcegepant and telcagepant, are effective in the treatment of migraine attacks. Increase of the neuropeptide CGRP during migraine and cluster headache attacks in the extracerebral circulation as measured in the external jugular vein (EJV) has been regarded as an established fact. Then in 2005, a study, using the migraine patients as their own controls, showed; however, no changes of CGRP in EJV. For migraine there is thus some uncertainty as to whether CGRP is increased in all migraine patients and more research is needed. In contrast, there are three 'positive' studies in cluster headache in which both sumatriptan, $\mathrm{O}_{2}$ and spontaneous resolution normalized CGRP. The source of an increase of CGRP in EJV is most likely a 'nervous vasodilatory drive' in the extracranial vascular bed. It remains an enigma how the observed increase of CGRP in the EJV fits into the mechanisms of migraine and cluster headache.
\end{abstract}

Keywords Migraine Cluster headache .

Calcitonin gene-related peptide $\cdot$ Extracranial circulation

\section{Introduction}

The involvement of calcitonin gene-related peptide (CGRP) in migraine pathophysiological mechanisms is

P. Tfelt-Hansen $(\varangle) \cdot$ H. Le

Department of Neurology, Danish Headache Centre, Glostrup Hospital, University of Copenhagen, 2400 Glostrup, Denmark e-mail: ptha@glo.regionh.dk convincingly shown by the facts that CGRP can induce migraine [1] and that two CGRP antagonists, olcegepant [2] and telcagepant [3, 4], are effective in the treatment of migraine attacks.

CGRP is a 37-amino-acid neuropeptide, first identified in 1982 [5]. CGRP belongs to a family of peptides which includes calcitonin, adrenomedullin and amylin. There is a wide distribution of CGRP immunoreactive structures in the peripheral nervous system and in the CNS [6, 7, 8]. CGRP-containing nerves innervate blood vessels in various regions of the body and the neuropeptide is a potent vasodilator. The physiological role of CGRP in the cardiovascular system is still not well understood [6]. In the cerebral circulation there is a dense supply of CGRP-containing nerve fibres which originate in the trigeminal ganglion [8, 9, 10] and the most pronounced action of CGRP is that of intracranial vasodilatation [11]. In addition, CGRP is also involved in pain sensations [12-14]. For general reviews of CGRP, see $[15,16]$.

Until recently it has been an established fact that CGRP is increased in external jugular blood when measured during attacks of migraine [17, 18] and cluster headache [19-21]. In 2005 a study with intra-patient control found, however, no change when CGRP was measured in the EJV during and outside of migraine attacks without aura [22]. This was the case with a new validated assay [23] and also with the very same assay used previously [17-19]. It has been stated that "CGRP is released in prolonged, severe attacks of migraine" [17, 24], but the duration of attacks was similar in these two studies $[17,22]$ (see below). Thus, the discrepancy between these studies remains unresolved until now.

In the following the available studies shall be analysed in depth followed by a conclusion. 


\section{Animal studies}

CGRP is involved in the transient arteriolar dilatation that is characteristic of cortical spreading depression (CSD) [25, 26]. One would therefore expect an increase of CGRP after CSD in the blood drained from the brain. This possibility was investigated in cats after CSD by sampling of blood for determination of CGRP from the EJV [27]. Blood was sampled during passage of a wave of CSD and 60 min later. No increase of CGRP was found [27]. It has been shown in cats that the internal carotid system is vestigial [27,28]. Most of the cerebral blood flow thus passes through the rete mirabile and the extracranial venous circulation [28]. It is therefore unlikely that the negative finding in this study could be attributed to the sampling in the EJV [27]. CGRP does not readily cross the blood brain barrier (BBB) [29, 30] and it was suggested that, even if CSD cause release of CGRP locally, it did not cross the BBB into the venous circulation in significant concentrations [27].

In contrast, trigeminal stimulation caused an increase (22-26\%) of CGRP in the EJV in cats in two studies [18, 31]. In one study there was $66 \%$ increase in substance P [31], whereas substance $\mathrm{P}$ was not measured in the other study [18]. The effect on CGRP levels could in one study be antagonized by administration of either sumatriptan or dihydroergotamine [18]. The effect of trigeminal stimulation is an increase in cerebral blood flow in cats [18, 32] and this increase could be reduced with sumatriptan and dihydroergotamine [18]. In contrast, electrical stimulation of the trigeminal ganglion in monkeys resulted in a frequencydependent decrease in external carotid resistance but had no effect on bulk flow and resistance in the internal carotid circulation [33]. Trigeminal ganglion stimulation in rats caused an increase of facial skin blood flow and this increase was inhibited by a CGRP antagonist [34]. Stimulation of trigeminal ganglion caused an increase of CGRP in jugular vein and this increase could be blocked by sumatriptan [35]. Stimulation of superior sagittal sinus in cats caused an $85 \%$ rise in CGRP in the EJV and a $300 \%$ rise in VIP, but no increase in substance P [36]. The increase of CGRP levels could be inhibited by avitriptan [37].

The animal studies thus indicate that CGRP is increased in the EJV if there is a 'nervous vasodilatory drive'. Due to the vestigial cephalic circulation of animals (see above), it is not possible to establish whether the observed increase of CGRP in EJV is the result of an intracranial or extracranial release of CGRP.

In one rat study, nitroglycerin (NTG) in doses of 2 and $50 \mu \mathrm{g} / \mathrm{kg}$ per min failed to change CGRP levels in the jugular vein indicating that NTG exerts its migraine- or cluster headache-inducing effect without involving this neuropeptide [38].

\section{Studies on external jugular venous blood in cluster headache}

For studies in which CGRP levels were measured in the EJV during cluster headache attacks, see Table 1 . In total 42 cluster headache attacks were investigated. Thirteen of these attacks were spontaneous attacks [19] and 29 were induced by sublingual nitroglycerin (NTG) [19, 20]. In the spontaneous attacks an increase in CGRP (mean $110 \pm 7 \mathrm{pmol} / \mathrm{l}$ ) in the EJV was found compared to controls $(41 \pm 6 \mathrm{pmol} / \mathrm{l})$ and there was a normalization of CGRP levels to $38 \pm 6 \mathrm{pmol} / 1$ after either subcutaneous sumatriptan $6 \mathrm{mg}$ or $\mathrm{O}_{2}$ inhalation [19] (Table 1). In the patients treated with pethidine there was no similar decrease in CGRP [19]. In the other studies [20, 21] the baseline values before administration of NTG were

Table 1 Overview of CGRP levels (pmol/l) in external jugular vein during cluster headache [15-17]

Cluster headache attacks

\begin{tabular}{lll}
\hline & During attacks pmol/1 & $\begin{array}{c}\text { After treatment (after spontaneous } \\
\text { resolution or outside attack) }\end{array}$ \\
\hline Thirteen patients with spontaneous cluster headache attacks [19] & $110 \pm 7$ & $38 \pm 6^{\text {a }}$ \\
Controls & $41 \pm 6$ & $22 \pm 2$ (after spontaneous resolution) \\
Twelve NTG induced cluster headache attacks [20] & $46 \pm 3$ & Baseline ${ }^{\mathrm{b}}: 20 \pm 2$ \\
Six NTG induced cluster headache attacks [20] & $50 \pm 4$ & $22 \pm 2^{\text {c }}$ \\
& Baseline $: 18 \pm 2$ & $22 \pm 2^{\text {c }}$
\end{tabular}

Results are given the mean $\pm \mathrm{SE}$

${ }^{a}$ Treatment with either subcutaneous sumatriptan $6 \mathrm{mg}$ or $\mathrm{O}_{2}$

b Baseline before sublingual nitroglycerin $0.9 \mathrm{mg}$

c Treatment with subcutaneous sumatriptan $6 \mathrm{mg}$ 


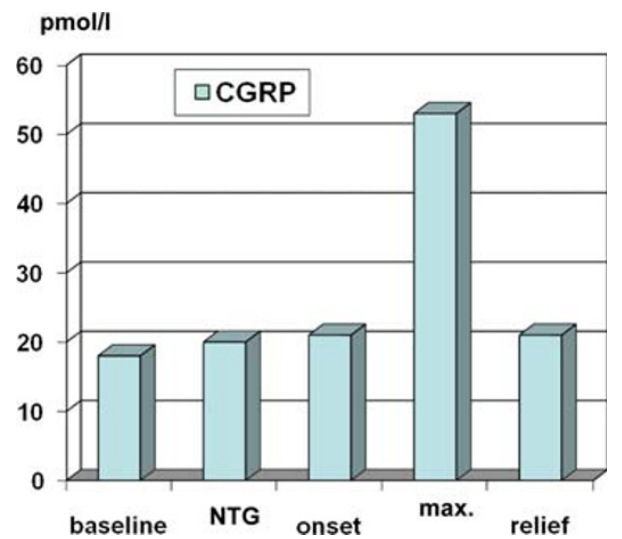

Fig. 1 CGRP levels (pmol/l) in external julular vein during nitroglycerin (NTG)-induced cluster headache. Note that NTG per se did not increase CGRP. At the start of the cluster headache attacks there was no increase in CGRP. At the maximum of attack CGRP increased twofold. Sumatriptan caused a normalization of CGRP levels, redrawn from [21]

determined. In both studies CGRP was more than doubled during the cluster headache attacks and spontaneous resolution of attacks or resolution after sumatriptan normalised the CGRP levels in EJV (Table 1) [20, 21]. The most extensive study [21] is illustrated in Fig. 1. It can be seen that vasodilator NTG per se did not increase the CGRP levels. Also at the beginning of the cluster headache attack there was no increase but after $1 \mathrm{~h}$ there was a doubling of the CGRP levels, and subcutaneous sumatriptan $6 \mathrm{mg}$ resulted in resolution of attacks and normalization of CGRP levels [21].

Thus, in contrast to migraine (see below), there is no doubt that CGRP is increased in EJV in cluster headache. In the three studies there is both an approximately twofold increase in CGRP during attacks and a normalization of CGRP occurred after spontaneous resolution or treatment with either sumatriptan or $\mathrm{O}_{2}$ [19-21].

\section{Studies on external jugular venous blood in migraine}

An overview of studies in which CGRP levels were measured in the EJV during migraine is given Table 2. In two studies, $(n=22)$ [17] and $(n=8)$ [18], from the Australian and Swedish group by Goadsby and Edvinsson there were increased levels of CGRP during migraine attacks (Table 2). During attacks CGRP decreased in seven out of eight patients responding to sumatriptan treatment [18] (Fig. 2). In contrast, in the Danish study $(n=17)$ with intra-patient comparison there was not even a tendency for an increase during migraine attack of migraine without aura (Table 2) [22]. This was the case where whether CGRP was measured with the same radioimmunoassay as used previously by Goadsby and Edvinsson [17, 18] or another sensitive assay [23]. There was an excellent intrapatient consistency between levels in EJV blood and cubital blood during migraine attacks with both assays indicating that no CGRP was released from the extracranial tissue [22].

These different findings in the EJV [17, 18, 22] are very difficult to reconcile. Are there differences in the patient populations? In the first two 'positive' studies a mixture of migraine with and without aura was investigated [17, 18], whereas in the 'negative' study only migraine without aura patients was studied [22]. In the first study the increased blood levels of CGRP was, however, similar during migraine with aura ( $92 \mathrm{pmol} / \mathrm{l}, n=10)$ and migraine without aura $(86 \mathrm{pmol} / \mathrm{l}, n=12)$ [17]. The controls levels were $<40 \mathrm{pmol} / \mathrm{l}$. The controls were 12 healthy females aged between 19 and 25 years [17]. The mean age in the migraine patients was 36 years (range 22-58 years) in the migraine patients [17] which was roughly similar to the patients in the Danish study: mean age 39 years, range 26-53 years [22]. The female/male sex ratios were $16 / 6$ [17] and 17/4 [22], respectively. The influence of sex and age was studied in one large study with cubital blood in 223 normal individuals and serum levels of CGRP (mean $36 \mathrm{pmol} / \mathrm{l}$ ) were unrelated to sex and age [23].

It has recently been stated [24] that "CGRP is released in prolonged, severe attacks of migraine" with a reference to [17]. The duration of the actual studied attacks were, however, similar in two of the studies $[17,22]$ with either 'positive' or 'negative' results, both median $3 \mathrm{~h}$, range 1-7 h [17] and mean $201 \mathrm{~min}$, range 95-305 min [22] whereas in the third study the median was $11 \mathrm{~h}$ and the
Table 2 Overview of CGRP levels (pmol/l) in external jugular vein during and outside migraine attacks $[13,14,18]$

Results are given the mean $\pm \mathrm{SE}$

a Treatment with subcutaneous sumatriptan $6 \mathrm{mg}$

\begin{tabular}{lll}
\hline Migraine attacks & During attacks pmol/1 & $\begin{array}{l}\text { After treatment (after spontaneous } \\
\text { resolution or outside attack) }\end{array}$ \\
\hline & $92 \pm 11$ & \\
\hline Ten migraine with aura (MA) [17] & $86 \pm 4$ & \\
Twelve migraine without aura (MO) [17] & $<40$ & $40 \pm 8^{\mathrm{a}}$ \\
Controls & $60 \pm 8$ & \\
Two MA and six MO [18] & 17 (range <10-42) & 16 (range $<10-28)$ (outside attacks) \\
Seventeen MO patients [22] & 33 (range 5-57) & 31 (range 14-61) \\
Assay I & & \\
Assay II &
\end{tabular}




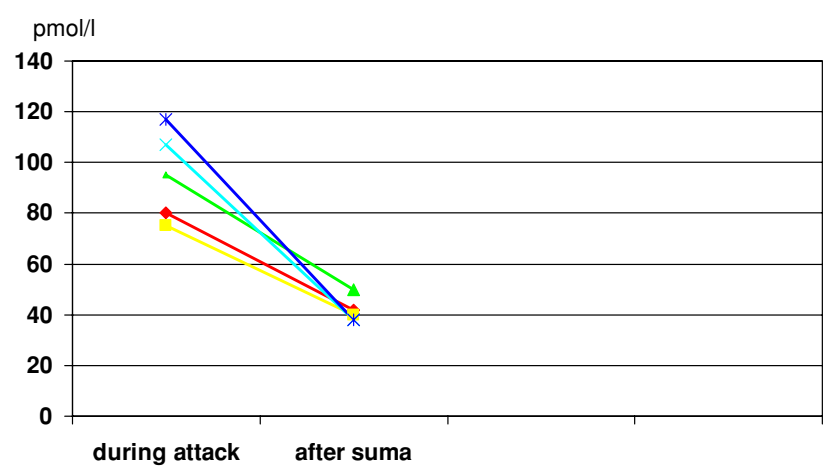

Fig. 2 Effect of subcutaneous sumatriptan $6 \mathrm{mg}$ on CGRP levels (pmol/l) in external jugular vein during migraine attacks $(n=8)$. Seven of eight patients responded to sumatriptan and in all these cases a decrease in CGRP levels was observed. One patient did not respond and there was no change in CGRP levels in this patient [18]

range was $1 \frac{1}{2} \mathrm{~h}$ to $3 \frac{1}{2}$ weeks (sic) [18]. The severity of headache in these three studies cannot be compared because in two of the studies with 'positive' results there are no data on headache severity $[17,18]$. In the study with intrapatient comparison, in which all patients fulfilled the diagnostic criteria for migraine without aura [39], the headache was severe in seven, moderate in 13 and mild in one patient [22]. The headache was unilateral in 19 patients [22]. There was no correlation between CGRP levels and severity and duration of attacks [22]. In the second 'positive' study $(n=8)$ no controls were used but CGRP levels before (mean $60 \mathrm{pmol} / \mathrm{l})$ and after subcutaneous sumatriptan (mean $40 \mathrm{pmol} / \mathrm{l}) \quad(P=0.016$, Sign test) were measured [18] (Fig. 2). It has been argued that the decrease in CGRP levels after sumatriptan could be an effect of the drug per se and not related to the antimigraine effect of sumatriptan [22]. The argument was based on an in vitro study, showing depression of CGRP in trigeminal cells by sumatriptan [40], but in human volunteers subcutaneous sumatriptan was without any effect on CGRP levels in the EJV [41]. The effect of sumatriptan on CGRP is thus most likely caused by an anti-migraine effect.

Thus, for migraine there is some uncertainty as to whether CGRP is increased in the EJV in all migraine patients. There are two 'positive' studies [17, 18], finding increased CGRP during migraine attacks, whereas the study with the best methodology, the intra-patient comparison, did not find even an indication of an increase in CGRP [22]. More studies are needed in order to settle the question of whether CGRP is increased in migraine.

One should not just repeat previous studies but go for the optimum design. This was used in one of the cluster headache studies [21]. CGRP was measured before, after provocation with NTG, at the beginning of attack, at the maximum of attack and after the attack was resolved [21].
Such a design used in migraine with i.v. NTG provocation of attacks [42, 43] is somewhat cumbersome, but since NTG triggers genuine migraine attacks [42, 43] it would once and for all settle the question of whether CGRP is increased in EJV during migraine attacks.

\section{Other studies with CGRP in cubital blood and internal jugular blood}

In two of the studies mentioned earlier [17, 22], no increase in CGRP in the cubital blood during migraine attacks was observed, whereas Gallai et al. found an increase of CGRP in 30 young, migraine-with-aura patients and 45 young, migraine-without-aura patients when studied during (mean $56+7$ pmol l) and outside attacks (mean $39 \pm 9$ pmol l) [41]. Since there are no indications that younger migraine patients have a different migraine pathophysiology than adults, the 'positive' study [44] remains unexplained for it is difficult to understand how an increase in CGRP in EJV (blood flow $160 \mathrm{ml} / \mathrm{min}$ ) could be picked up in the systemic circulation (minute volume $5,000 \mathrm{ml} / \mathrm{min}$ ). Similarly, no increase of CCGRP could be detected (detection limit $20 \mathrm{pmol} / \mathrm{l}$ ) [45] in the cubital vein during trigeminal thermocoagulation [46].

In nitroglycerin-induced migraine attacks there was a minor but significant increase $(6 \mathrm{pmol} / \mathrm{l})$ of CGRP level in cubital blood in one study [47] and there was a correlation between plasma levels of CGRP and severity of migraine [47]. In another study using nitroglycerin provocation migraine patients, that responded to intranasal sumatriptan $20 \mathrm{mg}$ had a minor $(17-15 \mathrm{pmol} / \mathrm{l}, n=6)$ decrease in CGRP level in cubital blood after sumatriptan, whereas this was not the case for non-responders (24-24 pmol/l, $n=13$ ) [48].

In one study CGRP levels in a cubital vein was unchanged after 10, 20 and 60 min nitroglycerin infusion [49].

In one small Italian study $(n=5)$ of CGRP in the internal jugular venous blood was found increased with a maximum after $1 \mathrm{~h}$ during repeated measurement up to 6 and $2 \mathrm{~h}$ after the migraine without aura attacks which were spontaneous and untreated [50]. In contrast, this was not the case in a small Danish study $(n=4)$ of CGRP in internal jugular venous blood studied during migraine aura [51]. The arterial CGRP levels were in all cases $(n=8)$ greater than the control value of $<40 \mathrm{pmol} / 1$ [51].

The specificity of the CGRP for primary headaches was demonstrated in one study of cervicogenic headache in which samples were taken from EJV and anticubital vein [52]. No difference was found between CGRP levels assessed on days with and without headache in neither of these veins [52]. 


\section{Which tissues does the EJV drain?}

The bulk of EJV blood flow comes from the extracranial tissue of head and face. In addition, the middle meningeal veins go through the foramen spinosum drain into the pterygoidal plexus [53] and this is a tributary to the EJV. The blood flow in the meningeal veins is likely to be comparable to blood flow in middle meningeal artery (MMA) Blood flow in the MMA in man is unknown. According to Fig. 940 in Spalteholz [53] the MMA is only a minor ramification of the external carotid artery. It is even smaller than the superficial temporal artery. Based on this indirect estimation blood flow in the middle meningeal veins contributes only to a small fraction of to blood in the EJV.

It is generally not known that $22 \%$ of the blood flow in the EJV comes from the cerebral circulation in man [54]. The venous circulation of the brain has numerous, but small, communication with extracerebral pathways. These are the emissary veins of the skull and the veins passing through the foramens of the base of the skull and the orbit and the veins which communicate with the pterygoid plexus [54]. Based on the possible increase of CGRP in internal jugular vein of an increase of $40 \mathrm{pmol} / \mathrm{l}$ found in one study [50], and based on a $22 \%$ contribution of cerebral blood to the EJV blood flow, it can be estimated that the contribution of cerebral blood can theoretically increase CGRP levels in EJV with 8 pmol/l. This calculation presumes that the analyses of CGRP are comparable, which is not the case (see Table 1). Anyway, this theoretical calculation indicates that only a smaller part of CGRP in EJV during cluster headache and possibly migraine is likely to come from the cerebral circulation (see Table 1).

In addition, the lack of increase in CGRP in EJV blood after CSD in cats [27] would indicate that the increased CGRP levels in the EJV during migraine with aura [17], in which CSD is the most likely the primary putative event $[55,56]$, is not derived from the brain. The CGRP in blood in EJV is thus most likely derived from part of the vasculature without BBB.

\section{Other relevant studies in man}

In this section, I will review some studies on arterial and blood flow changes relevant to a possible increase in CGRP in the EJV during migraine attacks and a certain increase during cluster headache attacks.

During 25 migraine attacks the temporal artery, as measured with ultrasound, during and outside attacks, on the symptomatic was not constricted whereas this was the case for the temporal artery on the non-symptomatic side [57]. In addition, the radial arteries were constricted during migraine attacks [57]. This indicates a general vasoconstrictory effect during the migraine attack [57]. Similarly, the temporal artery on the symptomatic side in cluster headache attacks $(n=9)$ was not constricted whereas this was the case on the non-symptomatic [58]. This indicates that there is an extracranial "vasodilatory drive" present on the symptomatic side during migraine and cluster headache [57, 58].

Only patients $(n=6)$ with facial flushing during trigeminal thermocoagulation showed an increase in CGRP in the EJV [31] whereas the patients $(n=3)$ without flushing showed no change. This supports the hypothesis that a "nervous vasodilatory drive" is necessary for release of CGRP from the extracranial vasculare bed. Thermographic studies have shown that facial flushing after thermocoagulation of Gasserian ganglion can be shown to be associated with increased skin temperature [59]. In cluster headache heat loss was increased from the affected orbital region. $\mathrm{O}_{2}$ treatment, which was effective in 22 of 25 patients, caused the asymmetry of heat loss to disappear [60]. Also in half-sided migraine attacks the ipsilateral-side had greater heat loss than the contralateral asymptomatic side [61].

That CGRP can be involved in flushing was also shown in a double-blind study in which intravenous administered human $\alpha$-CGRP $2 \mu \mathrm{g} / \mathrm{kg}$ per min caused flushing in the head and upper part of the body [62] whereas this was not the case after placebo. The flushing can be inhibited by the CGRP antagonist BIBN4096BS (olcegepant) [62] which also inhibited headache and extracranial vasodilatation [62].

\section{Conclusion}

Im migraine there are two 'postive' studies $[17,18]$ demonstrating increased CGRP levels in EJV during attacks whereas a negative study, using intra-patient comparison, found no change in CGRP in EJV [22]. For migraine there is thus some uncertainty as to whether CGRP in EJV is increased in all migraine patients; and more research, preferably with the intra-patient design with repeated measurements after provocation with NTG [21] (see above), is recommended.

For cluster headache there are three studies, one in spontaneous attacks [19] and two in nitroglycerin induced attacks [20, 21], which showed an increase in CGRP levels in EJV with normalisation after sumatriptan, $\mathrm{O}_{2}$ inhalation or spontaneous resolution.

The bulk of the blood in the EJV comes from the extracranial tissue and the face; only onefifth comes from the cerebral circulation [54]. Thus, changes in CGRP found in the EJV most likely reflect what is going on in this 
extracranial tissue that it drains. It has been shown with ultrasound that the temporal artery on the symptomatic headache is not constricted during migraine or cluster headache attacks whereas the artery is constricted on the contralateral side [57, 58]. These findings indicate that there is a 'vasodilator drive' on the symptomatic side counteracting a vasonstriction and at the same time releasing CGRP from nerves in this vascular bed.

How this fits into the migraine inducing effect of CGRP [1] and the efficacy of CGRP-antagonists in migraine [2-4] remains unclear. The issue whether increased CGRP in EJV, if present, is more than a 'marker for the trigeminovascular system remains to be investigated.

\section{Conflict of interest None.}

Open Access This article is distributed under the terms of the Creative Commons Attribution Noncommercial License which permits any noncommercial use, distribution, and reproduction in any medium, provided the original author(s) and source are credited.

\section{References}

1. Lassen LH, Tfelt-Hansen P, Jacobsen VB, Haderslev PA, Sperling B, Iversen HK, Olesen J (2008) The effect of intravenous infusion of human calcitonin gene-related peptide on middle cerebral artery and cerebral blood flow in migraine patients. J Headache Pain 9:151-157

2. Olesen J, Diener HC, Husstedt IW, Goadsby PJ, Hall D, Meier et al (2004) BIBN 4096 BS Clinical Proof of Concept Study Group Calcitonin gene-related peptide receptor antagonist BIBN $4096 \mathrm{BS}$ for the acute treatment of migraine. N Eng J Med 350:1104-1110

3. Ho TW, Mannix LK, Fan X, Assaid C, Furtek C, Jones CJ et al (2008) Randomized controlled trial of an horal CGRP antagonist, MK-0974, in acute treatment of migraine. Neurology 70:13041312

4. Ho TW, Ferrari MD, Dodick DW, Galet V, Kost J, Fan X et al (2008) Efficacy and tolerability of MK-0974 (telcagepant), a new oral antagonist of calcitonin gene-related peptide receptor, compared with zolmitriptan for acute migraine: a randomised, placebo-controlled, parallel-treatment trial. Lancet 372:21152125

5. Amara SG, Jonas V, Rosenfeld MG, Ong ES, Evans RM (1982) Alternative RNA processing in calcitonin gene expression generates mRNAs encoding different polypeptide products. Nature 298:240-242

6. Brain SD, Cambridge H (1996) Calcitonin gene-related peptide: vasoactive effects and potential therapeutic role. Gen Pharmacol 1996(27):607-611

7. Sexton PM (1991) Central nervous binding sites for calcitonin and calcitonin gene-related peptide. Mol Neurobiol 5:251-273

8. Edvinsson L, Goadsby PJ (1995) Neuropeptides in the cerebral circulation: relevance to migraine. Cephalalgia 15:272-276

9. Edvinsson L (1985) Functional role of perivascular peptides in the control of the cerebral circulation. Trends Neurosci 9:126-131

10. Uddman R, Edvinsson L, Ekman R, Kingman T, McCulloch J (1985) Innervation of the feline cerebral vasculature by nerve fibers containing calcitonin gene-related peptide: trigeminal origin and co-existence with substance P. Neurosci Lett 62:131-136
11. Ponyer DR (1992) Calcitonin gene-related peptide: multiple actions, multiple receptors. Pharmacol Ther 56:23-51

12. Hill RG, Oliver KR (2007) Neuropeptide and kinin antagonists. Handb Exp Pharmacol 177:181-216

13. van Rossum D, Hanisch UK, Quirion R (1997) Neuroanatomical localization, pharmacological characterization and functions of CGRP, related peptides and their receptors. Neurosci Biobehav Rev 21:649-678

14. Powell KJ, Ma W, Sutak M, Doods H, Quirion R, Jhamandas K (2000) Blockade and reversal of spinal morphine tolerance by peptide and non-peptide calcitonin gene-related peptide receptor antagonists. Br J Pharmacol 131:875-884

15. Wimalawansa SJ (1996) Calcitonin gene-related peptide and its receptors: molecular genetics, physiology, pathophysiology, and therapeutic potentials. Endocr Rev 17:533-585

16. Arulmani U, MaasenVanDenBrink A, Villalon CM, Saxena PR (2004) Calcitonin gene-related peptide and its role in migraine pathophysiology. Eur J Pharmacol 500:315-330

17. Goadsby PJ, Edvinsson L, Ekman R (1990) Vasoactive peptide release in the extracerebral circulation of humans during migraine attacks. Ann Neurol 28:183-187

18. Goadsby PJ, Edvinsson L (1993) The trigeminovascular system and migraine: studies characterizing cerebrovascular and neuropeptide changes seen in humans and cats. Ann Neurol 33:48-56

19. Goadsby PJ, Edvinsson L (1994) Human in vivo evidence for trigeminovascular activation in cluster headache. Neuropeptide changes and effects of acute attack therapies. Brain 117:427-434

20. Fanciullacci M, Alessandri M, Figini M, Geppetti P, Michelacci S (1995) Increase in plasma calcitonin gene-related peptide from the extracerebral circulation during nitro-glycerin-induced cluster headache attack. Pain 60:119-123

21. Fanciullacci M, Alessandri M, Sicuteri R, Marabini S (1997) Responsiveness of the trigeminovascular system to nitroglycerin in cluster headache patients. Brain 120:283-288

22. Tvedskov JF, Lipka K, Ashina M, Iversen HK, Schifter S, Olesen J (2005) No increase of calcitonin gene-related peptide in jugular blood during migraine. Ann Neurol 58:561-563

23. Schifter S (1991) Circulating concentrations of calcitonin generelated peptide (CGRP) in normal man determined with a new, highly sensitive radioimmunoassay. Peptides 12:365-369

24. Goadsby PJ (2008) Calcitonin gene-related peptide (CGRP) antagonists and migraine: is it a new area? Neurology 70:13001301

25. Colonna DM, Meng W, Deal DD, Busija DW (1994) Calcitonin gene-related peptide promotes cerebrovascular dilation during cortical spreading depression in rabbits. Am J Physiol 266: H1095-H1102

26. Wahl M, Schilling L, Parsons AA, Kaumam A (1994) Involvement of calcitonin gene-related peptide and nitric oxide (NO) in pial artery dilatation elicited by cortical spreading depression. Brain Res 637:204-210

27. Piper RD, Edvinsson L, Ekman R, Lambert GA (1993) Cortical spreading depression does not result in the release of calcitonin gene-related peptide into the external jugular vein of the cat: relevance to human migraine. Cephalalgia 13:180-183

28. Davis DD, Story HE (1943) Carotid circulation in the domestic cat. Publications of Field Museum of Nathional History 28:5-47

29. Edvinsson L, Nilsson E, Jansen-Olesen I (2007) Inhibitory effect of BIBN4096BS, CGRP(8-37), a CGRP antibody and an RNASpigelmer on CGRP induced vasodilatation in the perfused and non-perfused rat middle cerebral artery. Br J Pharmacol 150: 633-640

30. Edvinsson L, Tfelt-Hansen P (2008) The blood-brain barrier in migraine treatment. Cephalalgia 28:1245-1258

31. Goadsby PJ, Edvinsson L, Ekman R (1988) Release of vasoactive peptides in the extracerebral circulation of humans and the cat 
during activation of the trigeminovascular system. Ann Neurol 23:193-196

32. Goadsby PJ, Duckworth JW (1987) Effect of stimulation of trigeminal ganglion on cerebral blood flow in cats. Am J Physiol 253:R270-R274

33. Goadsby PJ, Lambert GA, Lance JW (1986) Stimulation of trgigeminal ganglion increases flow in the extracerebral but not the cerebral circulation of the monkey. Brain Res 381:63-67

34. Escott KJ, Beattie DT, Connor HE, Brain SD (1995) Trigeminal ganglion stimulation increases facial skin blood flow in the rat: a major role for calcitonin gene-related peptide. Brain Res 669:93-99

35. Limmroth V, Katsarava Z, Liendent B, Schmitz K, Diener HC, Michel MC (2001) An in vivo rat model to study calcitonin gene related peptide release following activation of the trigeminal vascular system. Pain 92:101-106

36. Zagami AS, Goadsby PJ, Edvinsson L (1990) Stimulation of the superior sagital sinus in the rat causes release of vasoactive peptides. Neuropeptides 16:69-75

37. Knight E, Edvinsson L, Goadsby PJ (2001) 4991W93 inhibits release of calcitonin gene-related peptide in the cat but only in doses with 5HT(1B/1D) receptor agonist activity. Neuropharmacology 40:520-525

38. Offenhauser N, Zinck T, Hoffmann J, Schiemann K, Schuh-Hofer S, Rohde W, Arnold G, Dirnagl U, Jansen-Olesen I, Reuter U (2005) CGRP release and c-fos expression within trigeminal nucleus caudalis of the rat following glyceryltrinitrate infusion. Cephalagia 25:225-236

39. Headache Classification Committee of the International Headache Society (2004) Classification and diagnostic criteria for headache disorders, cranial neuralgia and facial pain. Cephalalgia 24 (suppl 1):9-160

40. Durham PL, Russo AF (1999) Regulation of calcitonin generelated peptide secretion by serotonergic antimigraine drugs. J Neurosci 19:3423-3429

41. Hansen JM, Petersen J, Wienecke T, Olsen KS, Jensen LT, Ashina M (2008) Sumatriptan does no change calcitonin generelated peptide in the cephalic and extracephalic circulation in healthy volunteers. Abstract book. European Headache and Migraine nTrust International Congress, p 46

42. Afridi SK, Matharu MS, Lee L, Kaube H, Friston KJ, Frackowiak RS et al (2005) A PET study exploring the laterality of brainstem activation in migraine using glyceryl trinitrate. Brain 128: 932-939

43. Thomsen L, Kruuse C, Iversen H, Olesen J (1994) A nitric oxide donor (nitroglycerin) triggers genuine migraine attacks. Eur J Neurol 1:73-80

44. Gallai V, Sarchielli P, Floridi A, Franceschini M, Codini M, Trequattrini A, Palumbo R (1995) Vasoactive peptide levels in the plasma of young migraine patients with and without aura assessed both ictally and interictally. Cephalalgia 15:384-390

45. Ghatei MA, Stratton MR, Allen JM, Joplin GF, Polak JM, Bloom SR (1987) Co-secretion of calcitonin gene-related peptide, gastrin-releasing peptide and ACTH by a carcinoid tumour metastasazing to the cerebellum. Postgrad Med J 63:123-130

46. Schon F, Thomas DT, Jewkes DA, Ghatei M, Mulderry PK, Bloom SR (1987) Failure to detect plasma neuropeptide release during trigeminal thermocoagulation. J Neurol Neurosurg Psychiatr 50:642-643

47. Juhasz G, Zsombok T, Modos EA, Olajos S, Jakab B, Nemeth J et al (2003) No-induced migraine attack: strong increase in plasma calcitonin gene-related peptide (CGRP) concentration and negative correlation with platelet serotonin release. Pain 106:461-470

48. Juhasz G, Zsombok T, Jakab B, Nemeth J, Szolesanyri J, Bagdy G (2005) Sumatriptan causes parallel decrease in plasma calcitonin gene-related peptide (CGRP) concentration and migraine headache during nitroglycerin induced attack. Cephalalalgia 25:179-183

49. Ashina M, Bendtsen L, Jensen R, Schifter S, Olesen J (2001) Calcitonin gene-related peptide during nitric-oxide headache in patients with chronic tension-type headache. Eur J Neurol 8: 173-178

50. Sarchielli P, Alberti A, Codini M, Floridi A, Gallai V (2000) Nitric oxide, prostaglandin and trigeminal vasoactive peptides in internal jugular vein blood during spontaneous migraine attacks. Cephalalgia 20:903-918

51. Friberg L, Olesen J, Olsen TS, Karle A, Ekman R, Fahrenkrug J (1994) Absence of vasoactive peptide release from brain to cerebral circulation during onset of migraine with aura. Cephalalgia 14:47-54

52. Frese A, Schilgen M, Edvinsson L, Frandsen E, Evers S (2005) Calcitonin gene-related peptide in cervicogenic headache. Cephalalgia 25:700-703

53. Spanner R ed (1970) Spalteholz-Spanner Handatlas der Anatomie des Menchen, 16th edn. Second Part. Scheltema, Holkema, Amsterdam

54. Shenkin HA, Harmel MN, Kety SS (1948) Dynamic anatomy of the cerebral circulation. Arch Neurol Psychiatry 60:240-252

55. Hadjikhani N, Sanchez Del Rio M, Wu O, Schwartz D, Bakker D, Fischl B et al (2001) Mechanism of migraine aura revealed by functional MRI in the visual cortex. Proc Natl Acad Sci USA 98:4687-4692

56. Olesen J, Friberg L, Olsen TS, Iversen HK, Lassen NA, Andersen AR, Karle A (1990) Timing and topography of cerebral blood flow, aura, and headache during migraine attacks. Ann Neurol 28:791-798

57. Iversen HK, Nielsen TH, Olesen J, Tfelt-Hansen P (1990) Arterial responses during migraine headaches. Lancet 336:837-839

58. Nielsen TH, Tfelt-Hansen P, Iversen HK (2009) Asymmetry of temporal arterial diameter during spontaneous attacks of cluster headache. Headache 49:383-385

59. Drummond PD, Gonski A, Lance JW (1983) Facial flushing after thermocoagulation of the Gasserian ganglion. J Neurol Neurosurg Psychiatr 46:611-616

60. Drummond PD, Lance JW (1984) Thermographic changes in cluster headache. Neurology 34:1292-1298

61. Drummond PD, Lance JW (1984) Facial temperature in migraine, tension-vascular and tension headache. Cephalalgia 4:149-158

62. Petersen KA, Lassen LH, Birk S, Lesko L, Olesen J (2005) BIBN4096BS antagonizes human $\alpha$-calcitonin gene related peptide-induced headache and extracerebral artery dilatation. Clin Pharmacol Ther 77:202-213 